\title{
Adolescente privado de liberdade: um estudo dos argumentos do Judiciário para aplicação da medida socioeducativa de internação
}

\author{
Adolescents Deprived of Freedom: a study of the arguments of judiciary for the \\ implementation of socio-educational measure of deprivation of freedom
}

\section{Patricia Marcusso Giangarelli * Andréa Pires Rocha ${ }^{* *}$}

\begin{abstract}
Resumo:
O presente artigo apresenta os resultados da pesquisa desenvolvida para a conclusão do Curso de Especialização em Gestão de Centros de Socioeducação realizado no ano de 2010, na Universidade Estadual de Londrina. A investigação teve como objetivo conhecer os parâmetros utilizados pelos juízes para fundamentar a argumentação da aplicação da medida socioeducativa de internação de adolescentes que cometeram ato infracional. Para a realização desta análise, estabelecemos primeiramente um resgate histórico, político e legislativo referente à institucionalização de crianças e adolescentes no Brasil, mantendo um paralelo com acontecimentos mundiais relacionados ao tema, a partir de revisão bibliográfica sobre a temática. E, posteriormente, desenvolvemos uma pesquisa documental, tendo como fonte sentenças judiciais, das quais destacamos os argumentos apresentados pelos juízes e problematizamos os elementos identificados em nossa revisão bibliográfica. Assim, buscamos verificar se a lógica construída no Brasil de privar adolescentes de sua liberdade foi rompida após a instituição da doutrina da proteção integral ou mantém-se reproduzindo valores dos antigos "códigos de menores" que criminalizam a pobreza, os adolescentes e suas famílias.
\end{abstract}

Palavras-chave: Adolescente. Ato infracional. Privação de liberdade. Poder judiciário. Doutrina da proteção integral.

\begin{abstract}
:
The present article analyses which parameters have been used by judges to establish the argument of application by social educative punishment of internment by adolescents that have been committed infractional act. For the realization of this analyses we have established primary a historical, political and legislative rescue that refers to a institutionalization of children and adolescents in Brazil, keeping a parallel with world happenings related to the theme. Later, we
\end{abstract}

\footnotetext{
* Assistente Social formada pela Universidade Estadual de Londrina; Especialista em Trabalho Social com Famílias; Especialista em Gestão de Centros de Socioeducação; Mestranda do Programa de Pós Graduação em Serviço Social e Política Social/UEL pgiangarelli@gmail.com

** Docente do Departamento de Serviço Social da UEL; Mestre em Educação pela UEM; Doutoranda em Serviço Social pela UNESP-Franca. drea rocha@yahoo.com.br
} 
did the reading of judicial sentences making a cut out of the argument presented by the judge and discussed with the elements identifyed in our biographical review. In this way, reaching identifying if the logical built in Brazil by taking away adolescents of their freedom was broken after the institution of integral protection doctrine.

Keywords: Adolescent. Infractional act. Freedom privation. Judiciary power. Integral protection doctrine.

\section{Introdução}

O presente artigo traz os resultados da pesquisa desenvolvida para a conclusão do Curso de Especialização em Gestão de Centros de Socioeducação realizado no ano de 2010, na Universidade Estadual de Londrina, na qual problematizamos a questão da aplicação da medida socioeducativa de internação ${ }^{1}$ a adolescentes ${ }^{2}$ autores de atos infracionais, ${ }^{3}$ na perspectiva de verificarmos os parâmetros utilizados pelos juízes para fundamentar a argumentação da aplicação desta medida.

A nossa pesquisa encontra-se dividida em dois momentos. O primeiro refere-se à revisão bibliográfica com o objetivo de compreender a trajetória de institucionalização de crianças e adolescentes no Brasil até a promulgação do Estatuto da Criança e do Adolescente - ECA (BRASIL, 1990), situando a temática social e historicamente. O segundo momento contempla um levantamento do tipo pesquisa documental, como fonte de coleta de dados por meio de leitura das sentenças judiciais em que foi aplicada a medida socioeducativa de internação, tendo como amostragem o Centro de Socioeducação de Londrina II - Paraná.

Portanto, é a partir da análise documental que buscamos desenvolver uma mediação reflexiva apontando o quanto a reprodução dos valores construídos historicamente ainda estão presentes nas sentenças judiciais, mesmo depois do alcance de avanços significativos, pelo menos no que se refere ao fundamento da legislação atual.

\footnotetext{
${ }^{1}$ Medidas Socioeducativas previstas no artigo 112 do ECA (BRASIL, 1990): I- Advertência; II - Obrigação de reparar o dano; III - Prestação de serviços à comunidade; IV - Liberdade Assistida; V - Inserção em regime de semiliberdade; VI - Internação em estabelecimento educacional; VII - Qualquer uma das previstas no art.101, I a VI (Grifo nosso).

${ }^{2}$ Considera-se por adolescente a definição legal expressa no Estatuto da Criança e do Adolescente (BRASIL, 1990).

3 Conforme o ECA (BRASIL, 1990), considera-se ato infracional a conduta descrita como crime ou contravenção penal.
} 
É essencial considerarmos que a mudança de paradigma da doutrina da situação irregular ${ }^{4}$ existente nos Códigos de Menores, especialmente no de 1979, para a doutrina da proteção integral, ${ }^{5}$ introduzida na realidade brasileira por meio da promulgação do ECA, é considerada por especialistas, estudiosos e militantes da área dos direitos da infância e juventude, um grande avanço na maneira de interpretar as questões afetas à área. O rompimento com a doutrina da situação irregular em favor da doutrina da proteção integral contribuiu para a mudança de referenciais e paradigmas, com reflexo em diversas áreas de atuação com crianças e adolescentes, especialmente na questão infracional. Enfatizamos, portanto, que novas formas de proceder à aplicação de medidas socioeducativas para adolescentes que cometeram atos infracionais, principalmente a de internação, foram instituídas.

Ao adolescente que cometeu ato infracional só poderá ser aplicada a medida de internação com base nos critérios estabelecidos no artigo 122 do ECA, que são: cometimento de ato infracional mediante grave ameaça ou violência à pessoa, reiteração no cometimento de infrações graves e descumprimento reiterado e injustificável da medida anteriormente imposta. Estes critérios são importantes por definir e impedir a aplicação da medida de internação de maneira arbitrária, situação legitimada e recorrente quando ainda vigorava o Código de Menores (BRASIL, 1979).

No cotidiano da prática como assistente social em um Centro de Socioeducação, ${ }^{6}$ buscamos interpretar os argumentos, utilizados por juízes das Varas da Infância e Juventude $^{7}$ em suas sentenças, que justificam a aplicação da medida socioeducativa de internação a adolescentes que cometeram algum tipo de ato infracional.

Nessa lógica, estabelecemos nossa análise crítica por meio de comparações entre os parâmetros definidos em legislações anteriores à instituição da doutrina da proteção

\footnotetext{
${ }^{4}$ O Código de 1979 (BRASIL, 1979) adotou como doutrina a proteção ao menor em situação irregular, o que se reproduzia na prática, mediante sanções judiciais às crianças e adolescentes em situação de risco pessoal e social. Desta maneira, crianças e adolescentes não eram vistos como sujeitos de direitos e a lei era utilizada como forma de controle social dos pobres.

${ }^{5}$ A doutrina da proteção integral é introduzida no cenário nacional por meio do ECA (BRASIL, 1990) e entende todas as crianças e adolescentes como sujeitos de direitos.

${ }^{6}$ Centro de Socioeducação é a denominação das instituições que atendem adolescentes que cometeram atos infracionais e encontram-se privados de liberdade no Estado do Paraná.

${ }^{7}$ Em algumas Comarcas, principalmente as de pequeno porte, a Vara da Infância e Juventude está integrada com outras Varas como: Família, Cível, Criminal, Eleitoral e outras, pois há um único juiz para atender a todas as demandas. No entanto, não deixa de ter esta denominação.
} 
integral, buscando saber se a lógica construída historicamente no Brasil foi rompida a partir da promulgação da nova Lei. Desta forma, vemos que garantir a efetividade da referida Lei, pesquisar a prática de mecanismos criados pelo ECA, com o propósito de avaliá-los é essencial, pois somente assim o debate poderá avançar de maneira fidedigna, sobre a necessidade ou não de mudanças no conteúdo da Lei.

\section{Compreensão histórica sobre a legislação e a institucionalização de crianças e adolescentes no Brasil}

Para uma melhor compreensão acerca da história da legislação e institucionalização de crianças e adolescentes, apresentamos um breve relato histórico, a partir do qual buscamos analisar o entendimento sobre a infância desde o século XIX, até a promulgação do ECA no ano de 1990, estabelecendo um paralelo entre as discussões existentes no contexto mundial e no Brasil. ${ }^{8}$ Esta compreensão é importante porque deve respaldar a análise da nossa prática atual e das possíveis reproduções da lógica que autorizou a institucionalização de crianças e adolescentes neste país.

Em nossa revisão bibliográfica, identificamos três questões que aparecem como eixos centrais da discussão: a categoria infância e adolescência como categoria históricosocial; a construção, no Brasil, de uma cultura de institucionalização; e o fato de que a importância e a necessidade de cuidar de crianças e adolescentes como sujeitos de direitos vêm sendo construída a curtos passos e referendada pela lógica de controle social.

Entendemos que a compreensão histórica, social, econômica e ideológica de construção das categorias infância e adolescência constitui-se em um elemento fundamental para o entendimento da sua concepção. No mundo contemporâneo, ${ }^{9}$ pois, como exposto, a nossa compreensão é de que tais categorias não se encontram presentes entre nós, mas sim foram construídas com o passar do tempo pelas relações sociais existentes.

\footnotetext{
${ }^{8}$ É importante considerar que tais influências podem não ser visualizadas de forma direta.

9 Não nos interessa aqui aprofundar uma discussão exclusivamente ontológica, que compreende as categorias infância e adolescência em sua faixa etária, em suas mudanças biológicas e subjetivas, mas sim o seu lugar ocupado no mundo.
} 
Antes de iniciarmos a discussão contemporânea sobre as categorias infância e adolescência, é importante dizer que desenvolvemos leituras que tratam do histórico da política voltada para tais segmentos no Brasil desde o período da Colônia, tendo como referência Mary Del Priore (2004), Irene Rizzini e Irma Rizzini (2004, 2009a e 2009b), João Batista da Costa Saraiva $(2005 ; 2006)$. Estes autores mostram que as categorias infância e adolescência passaram a ser reconhecidas somente no século XVII. Anteriormente a este período crianças e adolescentes eram considerados como pequenos adultos. Do Brasil Colônia até os anos que antecederam a instituição da República, muito pouco se avançou em relação a este reconhecimento, principalmente quanto à responsabilidade penal. Assim, observa-se que as crianças da faixa etária dos 07 aos 14 anos poderiam ser privadas de sua liberdade, pelo julgamento do Código Penal da época. Cabe ressaltar que as instituições existentes na época eram coordenadas exclusivamente pela Igreja Católica, existindo a presença do Estado somente no repasse de recurso dos cofres públicos. ${ }^{10}$

Com a mudança política do Brasil Império para a República, o Estado brasileiro passa a assumir como sua a responsabilidade de garantir às pessoas o acesso aos direitos civis e sociais pela via das políticas públicas e não mais da filantropia, caridade etc. Isso significa dizer que o Estado passa a ter obrigações quanto ao investimento nas políticas públicas e quanto à qualidade dos serviços prestados.

Ainda no contexto da passagem do Império para a República, no final do século XIX, momento de mudanças políticas influenciadas pelas ideias positivistas de Augusto Comte, conforme relatam Mendez e Costa (1994, p. 17): “As diversas políticas de segregação dos menores, que começam a adquirir caráter sistemático a partir do século XIX, são legitimadas no contexto 'cientifico' do positivismo criminológico e nas conseqüentes teorias da defesa social que derivam desta corrente".

Cabe ressaltar que a mudança de regime político despertava na população a esperança do desenvolvimento do país, pois o sonho da emancipação havia se concretizado. $\mathrm{O}$ atendimento prestado a crianças e adolescentes se torna alvo de modificações, agora, as propostas de intervenção no segmento vinham do campo

\footnotetext{
10 Para maior conhecimento deste debate, sugerimos a leitura de Irene e Irma Rizzini (2004, 2009a e 2009b); Santos (2004) e Saraiva (2005).
} 
jurídico. ${ }^{11}$ Rizinni e Rizzini (2009a e 2009b) esclarecem em seus estudos sobre a constituição de uma política voltada ao atendimento a crianças e adolescentes que:

\begin{abstract}
Os últimos 20 anos do século XIX foram de intensa transformação no cenário político do país, com profundos reflexos na vida social brasileira. As mudanças ocasionadas pelos esforços no sentido de erradicar a escravatura e, concomitante, de se reestruturar o trabalho livre na sociedade da época mesclavam-se com o debate em torno da mudança de regime político que estava a caminho e se concretizou em 1889. [...] É dentro deste contexto que se pode entender o surgimento de uma crescente preocupação com a infância. Contudo, uma preocupação diferente da registrada no Brasil Império. Embora predominasse por algum tempo o enfoque de cunho religioso e caritativo na ação de assistência à criança, o Brasil República terá na esfera jurídica o principal catalisador da formulação do problema e da busca de soluções para o mesmo (RIZZINI; RIZZINI, 2009a, p. 107).
\end{abstract}

Nesse momento já se observa uma mudança graças ao movimento de juristas que sinalizava a importância e/ou necessidade de criar uma legislação específica para os menores de idade. Conforme Rizzini e Rizzini (2009a), entre os fatores que estimularam esta "preocupação", pode-se citar a mudança de regime político, a força do movimento internacional de reforma do Sistema Penal, a promulgação do novo Código Penal de 1890 e a revisão constitucional de 1891 em substituição das leis de 1830 e 1824 . Era o momento de abertura a influências advindas dos países que já adotavam o capitalismo como modelo econômico.

Se, por um lado, o atendimento à infância ganha importância e a discussão sobre esse tema no cenário nacional se amplia, chegando alguns juristas a fazerem uma análise das mudanças ocorridas no desenvolvimento do país devido ao modelo econômico vigente, por outro, o enfoque na decadência dos valores familiares e morais também é lembrado por este mesmo grupo, encabeçado pela elite governante. Assim, proteger as crianças é o lema, mas para que elas não se tornem uma ameaça à sociedade. ${ }^{12}$

\footnotetext{
${ }^{11}$ Como exemplo, podemos citar a lei de Abolição da Escravatura que em 1888 libertou os escravos, mas sem lhes assegurar qualquer garantia para o suprimento de suas necessidades. Esta população, sem muita alternativa, ganhou as ruas, incomodando as autoridades. Um projeto de "repressão da ociosidade" é apresentado, tendo como estratégia a "educação para a infância culpada" e o "amparo a velhice invalida e indigente" (RIZZINI; RIZZINI, 2009 a, p. 114).

${ }^{12}$ Desde o final do século XIX, o debate sobre a infância passou a ser temática mundial. Os maus tratos até então ignorados pela sociedade e pelo Estado, e muitas vezes cometidos pelas próprias famílias, ganham destaque mundial, especialmente a partir do caso Marrie Anne, ocorrido em Nova York. É a primeira vez que ocorre uma intervenção do Estado em favor de uma criança vítima de maus-tratos. Até então as agressões sofridas por uma criança que poderiam ter como argumento a disciplina, a obediência, a
} 
No Brasil, o que se denominava de "ideal republicano", na época, teve sua representação também no Novo Código Penal da República, que não se diferenciava muito do anterior (Código do Império), porém não punia criminalmente os menores de 09 anos e os que se encontravam na faixa etária de 09 a 14 anos eram punidos se a infração cometida por eles fosse entendida como praticada com “discernimento" ${ }^{13}$ A lógica do discernimento esteve sempre presente nas legislações para a infância. Deixou de ser um critério a ser considerado apenas com o ECA, em 1990. No entanto, ainda hoje nos deparamos com argumentos que remetem a essa lógica como forma de justificar a institucionalização de adolescentes. Como podemos observar em sentença proferida por um juiz de uma Vara da Infância e Juventude no ano de $2009,{ }^{14}$ que escreve:

Ao que tudo indica os infratores agiram conscientes de que estavam praticando ato ilícito. Presentemente, os representados estão com a personalidade voltada para a prática de atos infracionais e necessitam serem segregados para receberem tratamento psicológico, de drogadição e ressocialização ${ }^{15}$

Retomando o debate sobre a infância e a adolescência do início do século XIX, vimos que as discussões se aprofundavam no contexto nacional e caminhavam para a criação de legislação específica referente à infância e adolescência delinquente. 0 movimento internacional que propunha revolucionar o papel da justiça ganhou espaço no Brasil, influenciado pelos ideários positivistas. Este movimento trazia consigo o diagnóstico do aumento da criminalidade infantil como fato a ser considerado e modificado mediante a humanização do atendimento a esse segmento e da criação de tribunais e legislações específicos.

Assim, a sociedade do século XX parece convencida da importância de "salvar as crianças", caminhando para a construção do direito do menor, fundada no binômio

religião, a educação não causavam espanto. A questão do infanticídio passa a ganhar certa repulsa do Estado e da sociedade, bem como a questão dos maus-tratos. Este fato desperta uma preocupação mundial, cujo resultado é o nascimento do direito de menores e o surgimento da 1a Liga de Proteção à Infância (Save the children of world) (SARAIVA, 2005, p. 33).

${ }^{13}$ A definição de discernimento da época, segundo Santos (2004, p. 217), "é aquela madureza de juízo, que coloca o indivíduo em posição de apreciar com retidão e critério as suas próprias ações".

${ }^{14}$ Este exemplo é resultado de nossa pesquisa documental, apresentamos aqui, antecipadamente, por se tratar de caso explícito.

15 Texto extraído de uma sentença judicial e obtido a partir da pesquisa documental realizada nos autos processuais disponíveis no Centro de Socioeducação Londrina II (Sentença 10). Os dados da pesquisa, bem como a metodologia utilizada, são apresentados mais adiante neste artigo. 
carência/delinqüência, e se consolidou pela judicialização da questão da infância, trazendo consigo a terminologia "menor", que traduzia a infância desvalida, nas ruas, abandonada, perigosa (RIZZINI; RIZZINI, 2009a, p. 98).

A grande discussão em pauta no início do século XX era a de como institucionalizar os "menores". Um primeiro projeto de lei no ano de 1906 busca regulamentar a situação da infância e da delinquência (RIZZINI; RIZZINI, 2009a, p. 123). Cabe ressaltar que, um ano após a aprovação deste projeto de lei, eclode em São Paulo um "boom" demográfico devido à expansão das indústrias, com o consequente aumento das tensões sociais.

Em 1911, acontece, em Paris, o Congresso Internacional de Menores que contou com grande participação de juristas, tendo como resultado a influência para a criação de tribunais em toda a Europa e América Latina. As discussões que aconteceram no Congresso balizaram, posteriormente, a fundamentação da doutrina da situação irregular, que utilizava argumentos "com base no "amor" e na "proteção" para retirar as crianças e adolescentes do convívio de seus familiares e comunidade, educando-os moralmente e para o trabalho. ${ }^{16}$ Sobre o tema, acrescentam Mendez e Costa (1994, p. 19-20):

\begin{abstract}
São dois os motivos mais importantes, declarados pelo Congresso, que servem para legitimar as reformas da justiça de menores: as espantosas condições de vida nos cárceres, onde as crianças eram alijadas de forma indiscriminada com os adultos, e a formalidade e inflexibilidade da lei penal, que, obrigando o respeito, entre outros, aos princípios da legalidade e de determinação da sentença, impediam a tarefa de repressão-proteção própria do direito de menores. [...] Com o encerramento do Congresso abre-se uma nova etapa na política de "controle-repressão" de toda uma categoria de indivíduos cuja "debilidade e incapacidade" deveria ser sancionada jurídica e culturalmente.
\end{abstract}

Nesta mesma trajetória histórica, Irene e Irma Rizzini informam que em 1912, um ano após o acontecimento do referido Congresso e seis anos após a criação do primeiro projeto de lei, outro projeto é colocado em votação no Brasil, com a preocupação de classificar as categorias de menores com base nos conhecimentos da antropologia positivista e da psiquiatria, o que permitiu a imposição de julgamentos dos valores burgueses sobre as formas de organização e cuidados das famílias pobres em relação às

\footnotetext{
${ }^{16}$ O que se dizia em 1911 é que o juiz deveria ser como um bom pai de família na aplicação da lei. Posteriormente, vamos perceber como a lógica deste discurso vai contribuir para a institucionalização de crianças e adolescentes até os dias de hoje (MENDEZ; COSTA, 1994).
} 
suas crianças e adolescentes. "No que se refere aos menores, essa classificação transformou-se em um verdadeiro escrutínio de suas vidas, vasculhando-se aspectos do presente, do passado, de sua família e de sua personalidade" (RIZZINI; RIZZINI, 2009a, p. 123).

Posteriormente, houve a realização de outros congressos voltados ao tema, tanto internacionais como nacionais, ${ }^{17}$ até que em 1923 temos no Brasil a criação do 10 Tribunal de Menores, ${ }^{18}$ com sede no Rio de Janeiro.

\begin{abstract}
Num ambiente de agudos conflitos sociais que geravam uma recolocação subordinada no mercado internacional durante as primeiras décadas do século $\mathrm{XX}$, a criação dos tribunais de menores aparecia como a resposta mais adequada, apesar de insuficiente, para o controle de infratores potenciais da ordem (MENDEZ; COSTA, 1994, p. 24).
\end{abstract}

Em 1924, por meio do Decreto 16.388, cria-se o Conselho de Assistência e Proteção dos Menores, que tinha como premissa atender a todas as demandas advindas do "problema dos menores". Inevitavelmente tivemos a consolidação do primeiro código específico referente aos menores, no ano de 1927, conhecido como Código de Mello Mattos (BRASIL, 1927). Este Código incorporou algumas das leis (e decretos, projetos de lei etc.) já existentes, criando outras. No entanto, a lógica presente em seu texto baseavase na discussão já colocada em pauta no Brasil. Segundo Irene Rizzini e Irma Rizzini (2009a, p. 133), o Código era amplo e minucioso, contemplava todas as áreas, ultrapassando a esfera do jurídico:

\begin{abstract}
A impressão que se tem é que através da lei em questão procurou-se cobrir um amplo espectro de situações envolvendo a infância e adolescência. Parece-nos que o legislador, ao propor a regulamentação de medidas "protectivas" e também assistências, enveredou por uma área social que ultrapassava em muito as fronteiras do jurídico. O que o impulsionava era "resolver" o problema dos menores, prevendo todos os possíveis detalhes e exercendo firme controle
\end{abstract}

\footnotetext{
17 Congresso Americano da Infância, que aconteceu em Buenos Aires, no ano de 1916; III Congresso Americano em 1922; I Congresso Brasileiro de Proteção à Infância em 1922.

${ }^{18}$ A criação de um tribunal para menores leva em consideração duas questões: a primeira delas se refere à crítica existente sobre o juiz que aplicava a "pena" aos adolescentes, considerando apenas o fato e não o sujeito em sua individualidade, a segunda diz respeito à crença de que a avaliação judicial deveria considerar ou, melhor, se respaldar nos novos conhecimentos produzidos como nos de antropologia, psiquiatria e psicologia para tomar decisões. Consta que Mello Mattos foi o primeiro Juiz de Menores da América Latina, seu primeiro despacho foi em 06 de Março de 1924 (MENDEZ; COSTA, 1994)
} 
sobre os menores, através de mecanismos de "tutela", "guarda", "vigilância", "educação", "preservação" e "reforma".

O Código ${ }^{19}$ tratava da situação do "menor" de maneira individualizante, sua situação não tinha uma relação com fatores estruturais advindos do sistema, mas sim com a "incapacidade" da família em prover seu filho. A solução residia na institucionalização destas crianças e adolescentes, acreditando que desta maneira poderiam ter sua identidade restituída e assim contribuir para o desenvolvimento do país. Conforme nos mostram Mendez e Costa (1994), o Serviço de Assistência aos Menores - SAM foi criado em 1941, durante o governo centralizador, autoritário e corporativista de Getúlio Vargas, em sua fase mais autoritária. Esse serviço era vinculado ao Ministério da Justiça. A característica "absoluta" e "soberana" de governar se apoiava nas políticas sociais como estratégia para recrutar a população trabalhadora, mantendo, assim, seu controle. Portanto, foi um período de atenção a inúmeras reivindicações da população, como legislação trabalhista, obrigatoriedade de ensino básico, ampliação da previdência social entre outras.

Até este momento, a assistência prestada aos menores era criticada pelas autoridades e trabalhadores da área devido à desorganização que se perpetuava desde o início da República. A implantação do Juizado de Menores e de uma legislação específica (Código de Menores) não contribuiu para que esta organização acontecesse. A implantação do SAM foi a concretização de uma reivindicação de décadas pela criação de um órgão centralizador, capaz de organizar toda a assistência a este segmento.

Com a criação do Serviço de Assistência aos Menores (SAM), em 1941, pelo Governo Getúlio Vargas, as funções de organizar os serviços de assistência, fazer o estudo e ministrar o tratamento aos menores, foram retiradas da alçada

\footnotetext{
${ }^{19}$ Entre os princípios mais significativos do Código de Mello Mattos, destacam-se: instituição de um juízo privativo de menores; elevação da idade da irresponsabilidade penal do menor para 14 anos; instituição de processo especial para os menores em questão que envolvesse menores abandonados ou que estivessem vivendo fora dos padrões de normalidade, bem como a intervenção do Estado para suspender, inibir ou restringir o pátrio-poder, com imposição de normas e condições aos pais e tutores; regulamentação do trabalho de menores, limitando-se a idade de 12 anos, como mínima, para iniciação no trabalho, como também passa a proibir o trabalho noturno para menores de 18 anos; criação de um esboço de polícia especial de menores dentro de comissários de vigilância; proposta de criação de um corpo de assistentes sociais em que seriam designados delegados de assistência e proteção, com possibilidades de participação popular como comissários voluntários ou como membros do Conselho de Assistência e Proteção aos Menores e para estruturar racionalmente os internatos dos juizados de menores (MENDEZ; COSTA, 1994).
} 
dos juízes. Mantiveram-se a cargo destes a "fiscalização" do regime disciplinar e educativo dos internatos, de acordo com a legislação vigente (RIZZINI; RIZZINI, 2009b, p. 264).

O serviço caracterizava-se pela criação de instituições para abrigar os menores e tinha duas formas de gestão, uma mantida pelo Estado e outra pelas instituições "conveniadas" com o SAM, por meio do recebimento "per capita", que se proliferaram rapidamente.

Com o fim do período conhecido como Estado Novo (1937-1945), o Brasil havia rompido com a ditadura de Vargas e se reaproximava das inspirações liberais. No que se referia ao SAM, inúmeras denúncias vinham sendo apresentadas e o serviço era acusado de ser "escola do crime" e "sucursal do inferno". Devido às denúncias existentes, algumas feitas até mesmo por seus diretores, autoridades públicas, políticos e trabalhadores da área encabeçam um movimento de extinção do SAM e criação de outro serviço que se pusesse na contramão daquele.

Com a abertura do movimento citado acima, os juristas, agora do estado de São Paulo, novamente se apropriam do debate e chegam à conclusão de que o problema de menores é, antes de tudo, um problema de família, introduzindo uma nova discussão referente à política de atendimento à criança e adolescente.

Em um contexto de transformações, no Brasil, segundo Mendez e Costa (1994), as políticas sociais começam a responder a novas finalidades, servindo a interesses econômicos. Inúmeras instituições foram sendo criadas durante o governo, com proposta seja para substituição do SAM, seja para proteger a família e/ou a criança. ${ }^{20}$

Como sabemos, em 1964 o Brasil sofre o golpe militar, o qual trouxe mudanças expressivas nos aspectos econômicos e socioculturais do país. Nesse contexto, foi instituída a Política Nacional de Bem-Estar do Menor - PNBEM, que tinha como instituição executora central a Fundação Nacional de Bem-Estar do Menor - FUNABEM; e as Fundações Estaduais do Bem-Estar do Menor - FEBEM's, nos estados. A PNBEM foi instituída para substituir o atendimento prestado pelo SAM. No entanto, ainda segundo Mendez e Costa, esta política acabou não dando conta de romper com toda a truculência existente no sistema anterior.

\footnotetext{
${ }^{20}$ Entre elas citamos o INAM - Instituto Nacional de Assistência a Menores; Departamento Nacional da Criança -DNCr; Legião Brasileira de Assistência - LBA.
} 
Embora se propondo a substituir, através de uma nova política de atendimento, as práticas correcionais-repressivas do antigo SAM, a Funabem acabou sucumbindo a elas. Isto veio a ocorrer devido à incidência de fatores de natureza diversa nos momentos de transição, implantação e implementação da política que se propunha a superar as práticas do SAM (MENDEZ; COSTA, 1994, p. 128).

A orientação política de atendimento ao segmento criança e adolescente vinha da PNBEM que, em 1979, fortalece sua legitimidade a partir da promulgação do "Novo Código de Menores" - Lei 6.697/79 (BRASIL, 1979). Legislação esta que vinha ao encontro da perspectiva já existente. O referido Código dispunha sobre a assistência, proteção e vigilância de menores. Cabe ressaltar que, assim como o Código anterior, este também não se destinava a toda e qualquer criança e adolescente, mas sim aos "menores", ou seja, às crianças e adolescentes pobres. O novo Código institui uma nova categoria, reconhecida como "situação irregular". Sobre esta estabelece o Código em seu artigo 2ㅇ․

Para os efeitos deste Código, considera-se em situação irregular o menor:

I- privado de condições especiais à sua subsistência, saúde e instrução obrigatória, ainda que eventualmente, em razão de: a-) falta, ação ou omissão dos pais ou responsável; b-) manifesta impossibilidade dos pais ou responsável para provê-las;

II- vítima de maus tratos ou castigos imoderados impostos pelos pais ou responsável;

III- em perigo moral, devido a: a-) encontrar-se, de modo habitual, em ambiente contrário aos bons costumes; b-) exploração em atividade contrária aos bons costumes;

IV- privado de representação ou assistência legal, pela falta eventual dos pais ou responsável;

V- com desvio de conduta, em virtude de grave inadaptação familiar ou comunitária;

VI- autor de infração penal (BRASIL, 1979).

Segundo Saraiva (2005), esta doutrina pode ser definida como aquela em que os menores passam a ser objeto da norma quando se encontram em estado de "patologia social". A criação desta categoria representa os ideais militares da época. Segundo alguns autores, essa categoria deixa de ter a conotação de perigo para a sociedade, atribuída ao menor, e a substitui pela ideia de carência.

O enfoque correcional-repressivo, que via o menino como ameaça social, é substituído pelo enfoque assistencialista, que passa a percebê-lo como carente. 
Assim, a noção de periculosidade cede espaço central na estratégia de atendimento para a noção de privação de liberdade (MENDEZ; COSTA, 1994, p. 128).

A idéia expressa nesta categoria é a de que ao "menor" deve-se dar a chance de aprendizado moral, cívico, laboral, educativo e a instituição, no caso a Febem, é o espaço para a concretização desta chance. No entanto, este caráter assistencialista nunca foi soberano em face do caráter correcional-repressivo. ${ }^{21}$

Erigido sobre essa visão, o atendimento pautou-se pela tentativa de restituir à criança e ao jovem tudo o que lhe havia sido sonegado no âmbito das relações sociais. Isso levou a adoção dos centros de triagem, nas capitais, e das redes oficiais de internatos, no interior, como modelo básico de atendimento público ao menor em todo o país. Ocorre que a Funabem, ao ser criada, bem como muitas de suas congêneres estaduais, herdou do órgão antecessor prédios, equipamentos, materiais e sobretudo pessoal - e, com esse pessoal, a cultura organizacional do passado (MENDEZ; COSTA, 1994, p. 128-129).

Assim, o Estado brasileiro autoriza a institucionalização, ou melhor, a privação da liberdade de crianças e adolescentes, pela via da criminalização da pobreza e da judicialização da questão social, constituindo enormes instituições como única alternativa ao problema suscitado pela lei acima citada.

Neste tempo, de vigência do Código de Menores, a grande maioria da população infanto-juvenil recolhida às entidades de internação do sistema FEBEM no Brasil, na ordem de $80 \%$, era formada por crianças e adolescentes "menores", que não eram autores de fatos definidos como crime na legislação penal brasileira. Estava consagrado um sistema de controle da pobreza, que Emílio Garcia Mendez define como sociopenal, na medida em que se aplicavam sanções de privação de liberdade a situações não tipificadas como delito, subtraindo-se garantias processuais. Prendiam a vítima. Esta também era, por conseqüência, a ordem que imperava nos Juizados de Menores (SARAIVA, 2005, p. 51).

Desde o início da década de 1970 já assistíamos à formação de um movimento de rompimento com o caráter correcional-repressivo e assistencialista de atendimento,

${ }^{21}$ Assistindo ao filme nacional $O$ contador de Histórias (2009), dirigido por Luiz Villaça, sentimo-nos tomados de perplexidade. O filme conta a história (real) de Roberto Carlos Ramos, pedagogo e contador de histórias, que passou parte de sua infância na FEBEM de Belo Horizonte, devido aos apelos da política da década de 1960, que prometia o ensinamento da fé, educação, bons modos, esperança e moral e a chance da criança se tornar "doutor". A mãe do menino ficou seduzida pela ideia de proporcionar ao seu filho caçula o que não pôde dar aos outros oito filhos. 
coordenado pelos trabalhadores da área. A Organização das Nações Unidas já havia adotado em 1959 uma nova concepção jurídica denominada Declaração da Criança. Este documento é a afirmação dos direitos humanos fundamentais, da dignidade e do respeito. O ano de 1979 foi o Ano Internacional da Criança, ele deu origem à Convenção das Nações Unidas de Direito da Criança, consagrada em 1989. Porém, no Brasil, o novo Código de Menores não contemplava as premissas desta nova concepção que vinha sendo discutida em âmbito internacional. Esta ultrapassa a ideia de perigo, de ameaça e de carência, afirmando a criança e o adolescente como sujeitos de direitos.

Da segunda metade da década de 1970 em diante, já começamos a observar certa movimentação das camadas populares com a ação de sindicatos e de movimentos populares. A década de 1980 trouxe consigo um avanço e amadurecimento político desses movimentos. O Movimento Nacional de Meninos e Meninas de Rua, criado em 1982, teve uma importante participação na construção de uma nova forma de pensar a política social em favor das crianças e adolescentes.

Em 1988, temos a promulgação da Constituição Federal (BRASIL, 1988), conhecida como Constituição Cidadã, que se antecipou à Convenção das Nações Unidas, reconhecendo a criança e o adolescente como sujeitos de direitos, em fase peculiar de desenvolvimento, ${ }^{22}$ e instituindo a Doutrina da Proteção Integral em oposição à Doutrina da Situação Irregular. Assim, nas palavras de Saraiva (2005, p. 57), "o que se constata com este rompimento ideológico doutrinário, é que o país, o Estado e a sociedade é que se encontravam em situação irregular e não a criança e o adolescente".

Fruto da pressão e de reivindicações dos movimentos sociais da época, em 13 de julho de 1990 é sancionada a Lei 8.069/1990 (leia-se Estatuto da Criança e do Adolescente), uma versão brasileira da Convenção das Nações Unidas de Direito da Criança, ${ }^{23}$ com três princípios fundamentais: a criança e o adolescente como sujeitos de

\footnotetext{
22 Artigo 227 da Constituição Brasileira: "É dever da família, da sociedade e do Estado assegurar a criança e ao adolescente com absoluta prioridade, o direito à vida, à saúde, a alimentação, à educação, ao lazer, a profissionalização, à cultura, à dignidade, ao respeito, à liberdade e à convivência familiar e comunitária, além de colocá-los a salvo de toda forma de negligência, discriminação, exploração, crueldade e opressão" (BRASIL, 1988).

${ }^{23}$ Fruto deste mesmo processo, temos as seguintes normativas internacionais: Regras Mínimas das nações Unidas para a Administração da Justiça da Infância e da Juventude (Regras de Beijing) - 1984; Diretrizes das Nações Unidas para Prevenção da Delinquência Juvenil (Diretrizes de Riad) - 1990; Regras Mínimas das Nações Unidas para Proteção dos Jovens Privados de Liberdade - 1991.
} 
direitos; em condição peculiar de pessoas em desenvolvimento; que têm seus direitos assegurados com absoluta prioridade (BRASIL, 1990).

O rompimento com o termo "menor" permite que a lei contemple todos aqueles que se encontram em idade inferior a 18 anos. Assim, o que antes contribuía para a exclusão social pelo estabelecimento de "duas infâncias" (SARAIVA, 2006, p. 18), agora permite que o olhar a este segmento seja pela via dos direitos humanos.

No que se refere especificamente à responsabilidade penal juvenil, o ECA estabelece que os menores de 18 anos são inimputáveis, e aos maiores de 12 anos aplicam-se as medidas socioeducativas. No rol das medidas socioeducativas, encontramse advertência, obrigação de reparar o dano, prestação de serviços à comunidade, liberdade assistida, semiliberdade e internação. O ECA garante direitos individuais, o que se pode ver no capítulo II, contido nos artigos 106 a 109, assim como garantias processuais, como a defesa técnica, inexistente no Código de Menores de 1979.

Entre outras garantias cabe ressaltar que, com a promulgação do ECA, o adolescente só poderá ser apreendido e sancionado com a medida socioeducativa de internação mediante comprovação de materialidade da infração, em decisão escrita e fundamentada por autoridade judiciária, devendo ser a última alternativa a ser adotada, observados os princípios da brevidade e excepcionalidade. Aqui, pode-se dizer que o ECA busca combater a política de encarceramento "tragicamente presente na cultura "menorista" (SARAIVA, 2006, p. 176).

O que propomos aqui é verificar se os direitos referentes aos critérios para a aplicação da medida socioeducativa de internação estabelecidos pelo ECA, na perspectiva da responsabilidade penal juvenil, ${ }^{24}$ vêm sendo garantidos pelo Poder Judiciário.

\section{Análise das sentenças: os argumentos construídos para justificar a aplicação da medida socioeducativa de internação}

Para o desenvolvimento deste artigo, realizamos pesquisa documental no Centro de Socioeducação - Londrina $I{ }^{25}$ tendo como fonte a sentença judicial ${ }^{26}$ para identificar

\footnotetext{
${ }^{24}$ Sabemos da polêmica que norteia este tema, pois se trata das questões vinculadas às medidas socioeducativas como "direito penal juvenil", uma tese complexa que envolve vários elementos, em especial aqueles que se referem aos aspectos educativos e sancionatórios das medidas. Falamos aqui da "não criminalização" a partir do princípio da responsabilização.
} 
os argumentos utilizados pelos juízes, isso porque é nela que o juiz expõe os fundamentos de sua decisão, a partir das informações que possui, justificando qual é a medida socioeducativa mais adequada ao caso apresentado.

Foram analisadas 15 sentenças judiciais que aplicam a medida socioeducativa de internação. Optamos pelas sentenças judiciais como fontes, pois temos acesso às cópias destas cotidianamente, uma vez que são instrumentos de trabalho da equipe técnica (assistentes sociais, psicólogos, pedagogos e terapeutas ocupacionais), que atuam nas instituições de privação de liberdade para adolescentes, sendo documentação indispensável para o acolhimento do adolescente. Ressaltamos, ainda, que foi justamente pelo fato de termos acesso às sentenças que construímos nosso objeto de estudo.

A metodologia de pesquisa pautou-se em revisão bibliográfica e análise documental. Para o desenvolvimento da análise documental, tivemos como universo 80 prontuários técnicos, tendo como recorte o período de um ano. ${ }^{27}$ Estabelecemos um número de $15^{28}$ sentenças para que, dessa maneira, conseguíssemos abranger diferentes comarcas do estado do Paraná, evitando que a análise ficasse restrita a uma única comarca, ou seja, a um único Juízo. Cabe ressaltar que não utilizamos nenhum outro critério para escolha das sentenças, como idade, ato infracional praticado ou reiteração de atos infracionais.

Neste estudo os extratos das sentenças judiciais foram numerados aleatoriamente, com números que vão de 01 a 15, e são identificados para o leitor como Sentença n.01, Sentença n. 02 e assim por diante, até Sentença n. 15.

Estabelecemos previamente quatro categorias de análise, reiteradamente observadas e referentes aos parâmetros utilizados pelos juízes no momento de decidir sobre qual medida deve ser aplicada ao adolescente. Cabe ressaltar que as três primeiras

${ }^{25}$ O Centro de Socioeducação Londrina II, nosso espaço de atuação profissional, é uma instituição de privação de liberdade para adolescentes, aos quais a decisão judicial impôs a internação como medida socioeducativa.

${ }^{26}$ A sentença judicial é parte constituinte dos autos processuais que julgam o adolescente responsável por um ato infracional. Os autos são compostos por inquérito policial, parecer do ministério público, relatório técnico e parecer da defesa técnica. A mesma é proferida pelos juízes quando todos os elementos necessários a sua decisão constem nos autos.

27 Optamos por não informar o ano deste recorte para garantir o sigilo da pesquisa. Todavia, podemos informar que se trata de período recente.

${ }^{28}$ Das 15 sentenças judiciais analisadas nem todas serão apresentadas, visto que em alguma delas não identificamos argumentos que se remetiam as categorias previamente estabelecidas. 
categorias estão relacionadas, de forma direta, à redução das funções protetoras do Estado e ao tratamento das expressões referentes à questão social, consideradas como uma questão de lei, ou seja, a "incapacidade do indivíduo" em se tornar parte do mercado é criminalizada, no entanto, a diferença está na construção do argumento que o juiz encontra para justificar esta lógica. São elas:

- Situação de vulnerabilidade social do adolescente e de sua família e a criminalização da pobreza, como forma de culpabilizar os adolescentes e suas famílias sem considerar as contradições sociais;

- Discurso da "proteção" e do "amor" como forma de proteção social por meio da aplicação da medida socioeducativa de internação;

- A privação de liberdade como estratégia para manutenção da ordem social;

- Artigo 122 do ECA. ${ }^{29}$

É importante salientar que dentre as sentenças analisadas, algumas contemplaram apenas um dos argumentos citados acima, outras, apresentaram, de forma hibrida, mais de um argumento, ou seja, as categorias de análise são transversais. Especialmente, o que nos interessa é saber em qual lógica e em quais parâmetros os juízes se respaldam para a construção de seus argumentos, ao aplicarem a medida privativa de liberdade.

\section{Situação de vulnerabilidade social do adolescente e de sua família e a criminalização da pobreza}

No que concerne ao segmento criança e adolescente, seus direitos estão previstos nos artigos 227 e 228 da Constituição Federal e também no ECA. Resumidamente, estes artigos nos dizem que crianças e adolescentes encontram-se em fase peculiar de desenvolvimento e que, portanto, têm direitos sociais fundamentais garantidos para um desenvolvimento saudável. No entanto, o fragmento exposto abaixo, retirado de uma sentença judicial, não expressa essa compreensão por parte do magistrado.

\footnotetext{
${ }^{29}$ A medida de internação só poderá ser aplicada quando: I - tratar-se de ato infracional cometido mediante grave ameaça ou violência a pessoa; II - por reiteração no cometimento de outras infrações graves; III - por descumprimento reiterado e injustificável da medida anteriormente imposta. $\S 1$ o 0 prazo de internação na hipótese do inciso III deste artigo não poderá ser superior a três meses.§ 2‥ Em nenhuma hipótese será aplicada a internação, havendo outra medida adequada (BRASIL, 1990).
} 
[...] freqüenta as ruas e mocós desde os 10 anos de idade, quando iniciou o uso de drogas entorpecentes como inalantes, crack, maconha e usa tabaco e bebida alcoólica; já havia abandonado a escola e trabalhava como engraxate e sorveteiro ocasionalmente, quando tinha 11 anos de idade a situação se agravou, pois praticou homicídio de uma criança de 09 anos de idade. [...] ao que tudo indica, o infrator agiu consciente de que estava praticando ato ilícito. Presentemente a sua personalidade está totalmente voltada para a prática de atos infracionais e também ao vício das drogas entorpecentes, e o relatório social mostra que é irrecuperável, necessitando de atenção continuada em ambiente vigiado (Sentença n. 14).

O adolescente citado no fragmento acima havia cometido ato infracional análogo ao crime de furto; no argumento do juiz identificamos um rol de situações que permitiram que a situação deste chegasse aonde chegou, inúmeras violações de direitos, agora apontadas pelo juiz da Vara da Infância e Juventude, que vai marcando o histórico do adolescente e reconhecendo toda a condição de exposição de sua vida ao risco, pela ausência do Estado. No entanto, demonstra que, independente de toda essa tragédia, o adolescente possui condições de fazer suas escolhas de maneira consciente, sem considerar que todas as adversidades decorrentes da ausência de garantia de direitos pelo Estado não interferiu em sua escolha.

No histórico sobre a política voltada para o segmento infanto-juvenil desenvolvido neste texto, vimos que o rompimento com a doutrina da situação irregular foi o rompimento com as ambiguidades, com categorias vagas e de responsabilização da criança e do adolescente pela sua condição econômica, familiar e social. Todavia, assim como no argumento apresentado, outros fragmentos nos mostram como se posiciona o juiz a respeito de adolescente autores de ato infracional.

[...] Pelo estudo psicossocial verifica-se que a família do representado não tem conhecimento acerca das companhias deste, onde vai e o que faz quando não está em casa. Há, portanto, total falta de limites, o que sabidamente, leva os adolescentes a seguirem o caminho do mal [...] (Sentença n. 13)

[...] De acordo com os estudos apresentados pelo $\mathrm{SAI}^{30}$, que avaliaram a conduta social e personalidade do adolescente, pois não assume responsabilidades, não respeita limites, não estuda e não desenvolve qualquer atividade produtiva. Durante os tramites destes feitos chegou a ser internado em relação a outros autos e não se adequou aos limites impostos pelo Cense. 0 próprio genitor informou que o adolescente amadureceu no decorrer desses

\footnotetext{
${ }^{30}$ Serviço Auxiliar da Infância, órgão onde estão alocadas as equipes técnicas do Tribunal de Justiça do Estado do Paraná.
} 
processos que o adolescente se encontra novamente internado, desta feita sob a acusação de tráfico de entorpecentes (Sentença n. 5).

Quando falávamos do Código de Menores de 1979, dizíamos que a lógica que orientava os juízes de menores era a de sequestro dos conflitos sociais ou de judicialização da questão social. Com certeza, o ECA trouxe inúmeras contribuições no que se refere às garantias processuais, uma vez que limita o tempo de privação de liberdade em, no máximo, três anos, estabelecendo que privado de liberdade seja somente o adolescente cujo ato infracional fora comprovado a materialidade, garantindoIhes direito ao contraditório, entre outros. Porém, pelo que observamos nestas sentenças, a lógica construída historicamente, que autorizou a segregação de crianças e adolescentes no Brasil, não foi desconstruída com a promulgação da nova Lei.

\section{Discurso da "proteção" e do "amor" como forma de proteção social}

Segundo Mendez (1998), quando nos referimos à privação de liberdade para adolescentes, as considerações acerca do tema estão repletas de eufemismos, isso porque, embora o ECA, em um de seus artigos, tenha reconhecido a medida socioeducativa de internação como privação de liberdade, - a mesma privação de liberdade direcionada aos adultos -, muitos ainda não a enxergam desta maneira e insistem em dizer que, em alguns casos, este seria o único lugar para estudar, profissionalizar-se, aprender as regras sociais, pois uma vez que não é "pena", "sanção", tal intervenção estar-lhe-á fazendo um bem.

Essa forma de compreensão autoriza os operadores do sistema de garantia de direitos, entre eles o Poder Judiciário, a justificar a aplicação de uma medida privativa de liberdade como forma de proteção, de cuidado para com o adolescente. Esse discurso se apoia na lógica e na prática de um Estado, que tem reduzido cada vez mais os investimentos no fortalecimento estatal e omitindo-se em relação àqueles que se encontram em altíssimo grau de vulnerabilidade e insegurança social.

[...] Destaca-se, finalmente, que o objetivo primordial deste Juizado não é apenas apontar, reprimir o fato cometido pelo jovem infrator, mas também ressocializá-lo, educá-lo, para que após cumprir a medida retorne a sociedade com ideais distintos (Sentença n.2). 
[...] demonstra que se essa carreira infracional de [...] não for coarctada, mediante imposição de medida sócio-educativa mais severa, certamente ele não terá recuperação [...] (Sentença n. 12).

Assim, o magistrado encontra na privação de liberdade a possibilidade de garantir os direitos preconizados no ECA, argumentando que o objetivo primordial da aplicação da medida encontra-se na formação educacional, no seu tratamento para uso de drogas, na tentativa de impedir que ele venha a se envolver cada vez mais com o submundo da criminalidade a ponto de não haver mais retorno, conforme verificamos nas sentenças apresentadas a seguir:

[...] Como ele próprio afirmou, faz uso contumaz de drogas, sendo que qualquer outra medida que não a restritiva de liberdade fatalmente culminara no retorno do garoto ao uso de entorpecentes, com ulterior prática de atos idêntico ora reprovado. O pai do infante também sustentou com louvável sinceridade que devido aos inúmeros furtos não mais consegue trabalho para seu filho. O menor também não possui interesse algum a retomar seus, única circunstância que autorizaria alguma medida que não a internação (Sentença n. 11).

[...] Assim, é preciso, portanto, colocar fim a escalada criminosa de [...] sob pena de enveredar definitivamente para a vida do crime, na medida em que se vê incentivado sempre que uma providencia mais enérgica não for adotada. Já passa da hora de perceber que para cada ato seu há uma reação, e que se continuar com esse comportamento vai passar a maior parte de sua vida em estabelecimentos correicionais, privado do convívio da família, não deixando ainda de lembrar que a maioridade de avizinha, e que depois disso, as penas são cada vez piores (penitenciárias centros correicionais, etc) (Sentença n. 1).

Ou ainda numa versão mais apelativa...

[...] Vejo. Outrossim que o caso do adolescente [...] é especialíssimo, estando o mesmo necessitando, urgentemente de ser segregado da sociedade e colocado em regime de internação onde deverá receber tratamento necessário para sua reeducação e ressocialização (Sentença n. 14).

Nos trechos acima, podemos visualizar os eufemismos mencionados, nos argumentos, os quais distorcem os parâmetros existentes no ECA, referentes às circunstâncias nas quais dos adolescentes pode ser subtraído pelo Estado o direito à liberdade, permitindo que se justifique a privação de liberdade sob a alegação de proteção.

\section{A privação de liberdade como resposta à pressão social}


O argumento da manutenção da ordem social também tem sido grande aliado dos magistrados para justificar a aplicação da medida socioeducativa de internação. Observamos que a pressão da sociedade e de parte da mídia, que atua de maneira sensacionalista, solicitando respostas "mágicas" para um problema estrutural, tem contribuído para que este ator do sistema de garantia de direitos coloque-se como solucionador do clima de tensão social e encontre na segregação desses adolescentes uma resposta rápida e objetiva.

[...] a admitir que, se soltos, voltarão a delinqüir colocando em risco a ordem pública. [...] (Sentença n. 15).

[...] que os atos do representado em liberdade abalam a ordem pública desta comarca (Sentença n. 3).

[...] Assim, com a comprovação da prática da infração pelo representado, visando a recuperação do mesmo para o convívio social, e ainda a manutenção da ordem pública (destaque nosso), outro caminho não resta senão a aplicação da medida sócio-educativa de internação, medida que se mostra a mais adequada para se aplicar ao adolescente [...] (Sentença n. 1).

No entanto, o ECA estabelece, em seu artigo 122, as circunstâncias nas quais poderá ser aplicada à medida socioeducativa de internação, definindo que esta deve se adequar às características do fato ocorrido e não aos critérios subjetivos, tais como os de personalidade e da história do autor de ato infracional, como tentativa de impedir que medidas arbitrárias venham a ser aplicadas, como ocorria nos códigos anteriores, em que o adolescente era penalizado pela sua condição de vida.

Analisando os argumentos levantados nas 15 sentenças, observamos que estes ainda são os menos utilizados de maneira explícita. Porém, por outra ótica, vemos que esse discurso pode estar subjacente aos demais argumentos apresentados, uma vez que retirar das ruas um adolescente, alegando como causa a sua vulnerabilidade social e sua proteção, também tem como objetivo a manutenção da ordem social vigente.

\section{Sentenças justificadas no artigo 122 do ECA}

O adolescente autor de ato infracional, embora seja inimputável penalmente, poderá ser responsabilizado pelo ato cometido por meio da aplicação de qualquer uma das medidas socioeducativas previstas no artigo 112 do ECA de acordo com a gravidade 
do ato infracional que praticou. Para que seja aplicada a medida socioeducativa de internação ao adolescente deve ter cometido um ato infracional de violência ou grave ameaça contra a pessoa.

Segundo a referida legislação (BRASIL, 1990), os aspectos pessoais também podem e devem ser considerados como forma de analisar se a medida aplicada é a mais adequada ao caso. Porém, não como forma de responsabilizar o adolescente pela sua condição social ou de sua família, conforme pudemos.

Das 15 sentenças analisadas, em apenas 08 encontramos argumentos de juízes referenciados no disposto no artigo 122 do Estatuto, e destas em apenas uma identificamos explícita a construção do argumento em que se toma como parâmetro o ECA:

O adolescente apresentou comportamento incompatível com a convivência em sociedade disparando contra a vida de um semelhante em razão de discussões e brigas passadas. Conforme preceitua o ECA em seu art. 122, a internação é medida sócio-educativa que se impõe em casos de ato infracional cometido com violência contra a pessoa (Sentença n. 8).

Infelizmente, não obstante citarem o que está dito na Lei, as demais sentenças vacilam ao construir argumento com base nas outras categorias. Aqui, podemos observar que a justificativa apresentada pelo Judiciário apenas se apóia no artigo da Lei que diz em quais situações é autorizado a privação de liberdade para adolescentes.

Pode-se dizer que outros aspectos também foram avaliados para a aplicação da medida, no entanto, estes não se sobrepuseram a gravidade do ato infracional.

\section{Conclusões}

Este estudo nos permitiu apontar a problemática existente na forma como o Poder Judiciário interpreta as leis referentes à aplicação da medida socioeducativa de internação. Embora não se utilize mais o termo "menor", a lógica da legislação "menorista" encontra-se subjacente aos argumentos apresentados pelos juízes, pois podemos identificar, no discurso presente nas sentenças judiciais, elementos relacionados à situação familiar e econômica e à proteção dos adolescentes para a construção de uma vida digna pelo estudo e aprendizado de um ofício,e também pela 
manutenção da ordem pública. Observamos que a aplicação da medida socioeducativa de internação ao adolescente, ou seja, a privação de sua liberdade, não está vinculada expressamente ao ato infracional cometido, mas sim ao controle social de uma população que ainda é vista como de risco iminente para a sociedade.

Pudemos observar também a percepção equivocada da medida de internação, segundo a qual acredita-se que, após o cumprimento da mesma uma mudança considerável, poderá ocorrer na vida do adolescente, sem garantia de seus direitos quando em situação de vulnerabilidade social, sendo eles(as) autores de atos infracionais ou não.

Cabe lembrar que toda a discussão sustentada neste artigo mostrou que a privação da liberdade ainda se destina aqueles que tiveram e continuam tendo seus direitos cerceados e que, portanto, a prática de atos infracionais não deixa de ter uma relação direta, embora inconsciente, com a configuração de uma sociedade capitalista, que por regra necessita da exclusão social para manter o sistema. Ou seja, esse adolescente nunca ocupou um lugar de reconhecimento na sociedade, ele sempre foi invisível. Portanto, acreditar que retirar um direito para proporcionar outro(s) pode ser eficaz é complicado.

Outra questão debatida aqui se refere à aplicação inapropriada da medida, com outros objetivos, tais como tratamento da dependência de drogas, atendimento psicológico, escolarização e demais serviços e intervenções que deveriam ser garantidos ao adolescente quando ele se encontra gozando de sua liberdade, no convívio com sua família e comunidade. Aqui cabe um parênteses: vimos na pesquisa algo que não foi foco de nossa discussão, porém, cabe destacar que, em vários casos, os magistrados citam o relatório técnico que compõe os autos, na construção de seu argumento. No entanto, a forma como foram colocados nos mostrou que tais relatórios algumas vezes também reproduzem os princípios menoristas, outras vezes mostram-se frágeis em sua argumentação, passíveis de serem utilizados e interpretados de maneira equivocada pelo Judiciário.

Por fim, percebemos a fragilidade do sistema de garantia de direitos, aqui representado pelo Poder Judiciário, pois não se tem configurado como um sistema que garante os direitos do segmento infantojuvenil. Essencialmente, pudemos observar neste estudo que a promulgação de uma nova Lei (Estatuto da Criança e do Adolescente) até o 
momento não deu conta de romper com a lógica da institucionalização para resolver as questões afetas às crianças e adolescentes, construída no Brasil desde sua fase colonial.

Por se tratar de lei, de Poder Judiciário e muito pouco se questionar a posição tomada pelos agentes desse poder de Estado na defesa de direitos, a nossa intenção é continuar com o olhar voltado para esses atores, observando e denunciando a lógica que os tem guiado, pois, se atualmente nos encontramos em um momento delicado, que tem dado indícios de uma possível retomada da doutrina da situação irregular, podemos dizer que a postura adotada por alguns tem contribuído para este retrocesso.

\section{Referências}

BRASIL. Constituição (1988). Constituição da República Federativa do Brasil. Brasília, 1988. . Decreto - Lei 17.943-A, de 12 de outubro de 1927. Código de Menores. Rio de Janeiro, 1927.

Decreto n. 16.388 de 27 de fevereiro de 1924. Aprova o regulamento do Conselho de Assistência e proteção dos Menores. Brasília, 1924.

. Lei 6.697, de 10 de outubro de 1979. Código de Menores. Brasília, 1979.

. Lei 8.069 de 13 de julho de 1990. Estatuto da Criança e do Adolescente. Brasília, 1990.

MENDEZ, E. G. Infância e cidadania na América Latina. São Paulo: Hucitec, 1998.

MENDEZ, E. G.; COSTA, A. C. G. Das necessidades aos direitos. São Paulo: Malheiros, 1994.

O CONTADOR de histórias. Produção de Francisco Ramalho Junior e Denise Fraga. São Paulo, Warner Bros. Pictures, 2009. 90 min. 1 DVD.

PRIORE, M. D. (Org.). História das crianças no Brasil. 4. ed. São Paulo: Contexto, 2004.

RIZZINI, I.; RIZZINI, I. A institucionalização de crianças no Brasil: percurso histórico e desafios do presente. Rio de Janeiro: PUC-Rio, 2004.

. Crianças e menores - do pátrio poder ao pátrio dever. um histórico da legislação para a infância no Brasil. In: RIZZINI, I.; PILOTTI, F. (Org.). A arte de governar crianças: a história das políticas sociais, da legislação e da assistência à infância no Brasil. 2. ed. São Paulo: Cortez, 2009a. p. 97-149.

Meninos desvalidos e menores transviados: a trajetória da assistência pública até a Era Vargas. In: RIZZINI, I.; PILOTTI, F. (Org.). A arte de governar crianças: a história das 
políticas sociais, da legislação e da assistência à infância no Brasil. 2. ed. São Paulo: Cortez, 2009b. p. 225-286.

SANTOS, M. A. C. Criança e criminalidade no início do século. In: PRIORE, M. D. (Org.). História das crianças no Brasil. 4. ed. São Paulo: Contexto, 2004. p. 210-230.

SARAIVA, J. B. C. Adolescente em conflito com a lei: da indiferença à proteção integral: uma abordagem sobre a responsabilidade penal juvenil. 2. ed. Porto Alegre: Livraria do Advogado, 2005.

Compêndio de direito penal juvenil: adolescente e ato infracional. 3. ed. Porto Alegre: Livraria do Advogado, 2006.

Recebido em: 05/10/2011 